\title{
Capacitor Clamped Inverter Based D-STATCOM for Voltage Regulator in Power Quality Improvement for Distribution Grids
}

\author{
K. Dwarakesh, Rathika R, Aarthi Suriya S
}

\begin{abstract}
A tale delicate exchanging interleaved coupled-inductor help converter is proposed in this paper. Just a solitary dynamic delicate exchanging module is expected to at the same time accomplish the delicate exchanging property of the two switches in the interleaved coupled-inductor support converter. The better proficiency is accomplished with the less segments and cost. The two primary switches can accomplish the ZVT turn-on and littler current mood killer at the same time when the single dynamic delicate exchanging module is dynamic. Because of the coupling normal for the inductors, the voltages over the two inductors are changed simultaneously; in this manner, the comparable circuit is equivalent to the parasitic capacitors of the two primary switches in parallel to resound with the helper inductor. By coupling two info inductors, the volume and cost of the circuit can be diminished. The interleaved coupled-inductor topology can likewise decrease the info and yield current swells and offer the information and yield flows. The working modes, investigation, and structure of the proposed circuit have been talked about in this paper. Reproduction and tests are at last led to check the legitimacy of the proposed circuit. [19],[20],[21]
\end{abstract}

Keywords : D-STATCOM,LCL Passive Filter, Power Quality, Dip.

Total Harmonic Distortion(THD), Vsc, Voltage Sag, Voltage

\section{INTRODUCTION}

COUPLED-inductor interleaved help converters are a work in progress for high-current, high-control applications running from car to appropriated age. The working methods of these coupled-inductor converters can be mind boggling. This paper shows an examination of the different consistent current (CCM) and broken current (DCM) methods of activity of the coupled-inductor interleaved two-stage help converter. The different CCM and DCM of the converter are recognized together with their submodes of activity. The standard discrete-inductor interleaved two-stage lift can be viewed as a subset of the coupled-inductor converter family with zero shared coupling between the stages. The unfaltering state working attributes, conditions and waveforms for the numerous CCM and DCM will be introduced for the converter family.
Flaw determination framework for a staggered inverter utilizing a primary part neural system is proposed in this section. It is hard to analyze a Multilevel-Inverter Drive framework utilizing a math work model in light of the fact that MLID frameworks comprise of all the more at that point exchanging gadgets and their framework unpredictability has a nonlinear factor. The Principal Component Analysis (PCA) is used to lessen the neural system info size. A lower dimensional info space will likewise for the most part diminish the time important to prepare a neural system, and the decreased clamor may improve the mapping execution is introduced by Tolbert [01]-2007. [14],[ 16], [18]

Another sort of staggered inverter is presented which is made by falling two 3-stage 3-level inverters utilizing the heap association, yet requires just a single DC voltage source. This new inverter can work as a 7-level inverter and normally parts the power transformation into a higher-voltage lower-recurrence inverter and a lower-voltage higher-recurrence inverter. New control techniques are portrayed including both joint and separate control of the individual three-level inverters is recommended by Peng [02]-2004. [13], [15] ,[ 17]

Staggered converters-An empowering innovation for high-control applications is given by Rodriguez. Staggered converters are viewed as today as the best in class control transformation frameworks for high-power and power-quality requesting applications. This work shows an instructional exercise on this innovation, covering the working guideline and the distinctive power circuit topologies, balance strategies, specialized issues and industry applications. Exceptional consideration is given to built up innovation effectively found in industry with additional inside and out and independent data, while ongoing advances and best in class commitments are tended to with helpful references[03]-2009. D-STATCOM Is Most Usable Shunt Compensating Custom Power Device That Used For Power Quality Improvement. This Device Generally Connected At Load End Where Power Quality Improvement Is Needed. [8],[10],[12] 


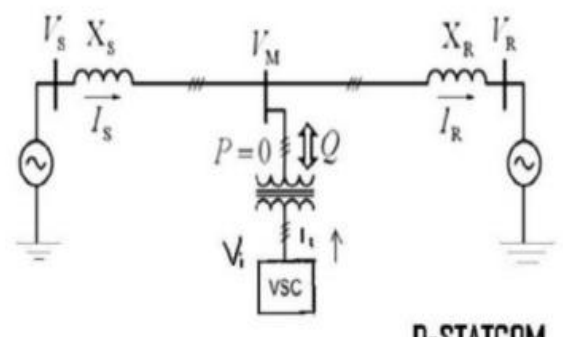

Fig.1. -STATCOM Structure

Greatest power point following in a one-cycle-controlled single-organize photovoltaic inverter is recommended by Fortunato. Structure imperatives that record for various climate conditions are received. The advancement calculation additionally gives helpful data concerning the framework affectability as for every one of the controller parameters. This permits the structure of a most extreme power point following irritate and watch controller that essentially improves inverter performance[4]-2008.

A Survey on fell staggered inverters is given by Gopakumar. This trademark enables one to accomplish great yield voltages and information flows and furthermore exceptional accessibility because of their characteristic part excess. Because of these highlights, the fell staggered inverter has been perceived as a significant option in the medium-voltage inverter showcase. This work exhibits a study of various topologies, control systems and regulation procedures utilized by these inverters [5]-2010.

The real segments of a DSTATCOM are appeared in Fig.1.2. It comprises of a dc capacitor, at least one inverter modules, an air conditioner channel, a transformer to coordinate the inverter yield to the line voltage, and a PWM control system.

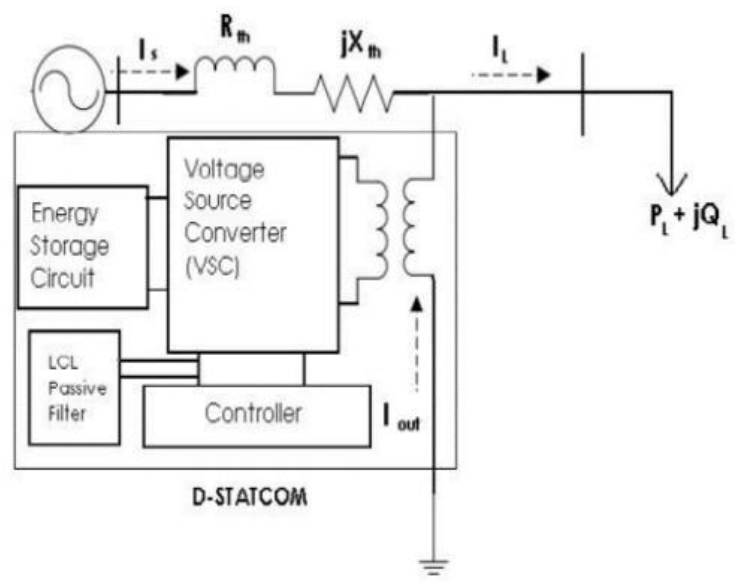

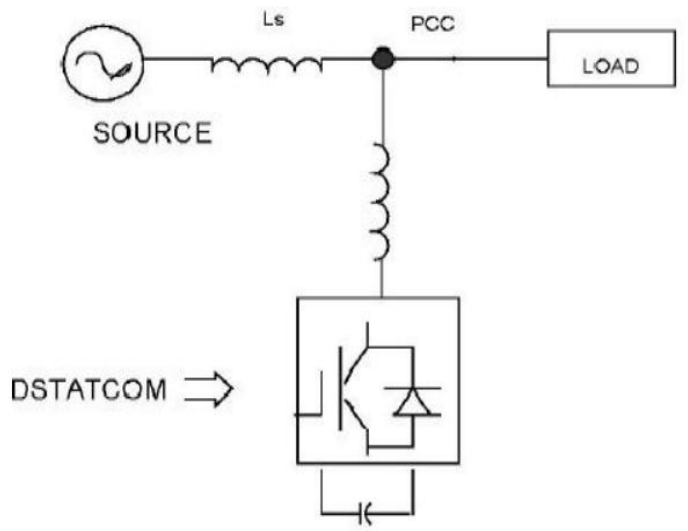

Figure 2 Block diagram of DSTATCOM circuit

Decoupled control framework for fell h-connect staggered converter based STATCOM is displayed by Farivar. In customary control frameworks for a static synchronous compensator (STATCOM) in view of a fell $\mathrm{H}$-connect staggered converter, the activity of individual voltage controllers that parity capacitor voltages can change the yield of a bunch voltage controller and a present controller because of a coupling impact. In this work, first, the conditions that take out this coupling impact are inferred, and after that, a control framework that implements the determined decoupling conditions is proposed [6]-2015. [7],[9], ,11]

Measured Cascaded H-Bridge Multilevel PV inverter with dispersed MPPT for network associated applications is given by Bailu. To acknowledge better usage of PV modules and augment the sunlight based vitality extraction, an appropriated most extreme power point following control plan is applied to both single-and three-stage staggered inverters, which permits free control of every DC-interface voltage. For three-stage framework associated applications, PV bungles may present uneven provided control, prompting lopsided matrix current. To unravel this issue, a control conspire with balance remuneration is likewise proposed[8]-2014. [2 ],[ 4],[6]

A FGPA based propelled control procedure of a lattice tied PV CHB inverter is exhibited by Coppola. The circuit topology comprises of an appropriate number of intensity cells (H-connect setup) associated in arrangement and provided by individual PV modules. The phones' state is identified with the need of charging or releasing a specific cell significantly more than the others by computing the voltage mistake at every dc-interface (e.g., by considering the contrast between the most extreme power point following (MPPT) reference and the deliberate amount). A committed P\&O MPPT grants to control freely the voltage of every dc-interface; subsequently, expanding the power extraction even in befuddled conditions[9]-2015.

A Generalized Cascaded Multilevel Inverter Using Series Connection of Sub-Multilevel Inverters is given by Kangarlu. Utilization of staggered inverters for a higher power reason in businesses has turned out to be progressively prominent. This is somewhat a result of top notch yield waveform of staggered 
inverters in examination with two-level inverters. In this paper, at first another topology for submulti level inverter is proposed and after that arrangement association of the submulti level inverters is proposed as a summed up staggered inverter. The proposed staggered inverter uses diminished number of exchanging devices[10]-2013.

Investigation, control and structure of cross breed Grid associated inverter for sustainable power source age with power quality molding is displayed by Wang. Contrasted and the regular inductive-coupling matrix associated inverter (IGCI) and capacitive-coupling lattice associated inverter (CGCI), the proposed HGCI has unmistakable attributes of wide operational range and low DC-interface working voltage. In light of these unmistakable qualities, the framework cost and operational expense can be decreased. In addition, it can move the dynamic power and repay receptive power, lopsided power and consonant power simultaneously[11]-2017.

THD in Cascade Multilevel Inverter Symmetric and Asymmetric is recommended by Vargas. This work centers around the similar investigation of fell staggered inverter whit two inverter cells, symmetric (5 levels) and awry (7 and 9 levels). These inverters are actualized without changes in the Power Semiconductor Devices, just alter the control stage and info supply voltages in the cells[12]-2011.

Another network associated PV framework dependent on fell $\mathrm{H}$-connect semi $\mathrm{z}$ source inverter is given by Dongsen. Another plan for lattice associated photovoltaic (PV) interface by mix of a semi $\mathrm{Z}$ source inverter (qZSI) into fell $\mathrm{H}$-connect $(\mathrm{CHB})$ is proposed in this work. The proposed plan empowers PV string voltage lift to a higher level, and takes care of the lopsidedness issue of DC-interface voltage in conventional $\mathrm{CHB}$ inverters. A staggered voltage waveform of inverter yield is produced by an improved stage moved sinusoidal heartbeat width adjustment (PS-SPWM) calculation, which brings shoot-through states into the regular zero states to control qZS-CHB module[13]-2013.

Another fell exchanged capacitor staggered inverter dependent on improved arrangement parallel change with less number of parts is given by Zamiri. The proposed topology comprises of another changed capacitor DC to DC converter (SCC) that has help capacity and can charge capacitors as self-adjusting by utilizing the proposed double hilter kilter calculation and arrangement parallel transformation of intensity supply. The proposed SCC unit is utilized in new arrangement as a sub staggered inverter (SMLI) and afterward, these proposed SMLIs are fell together and make another fell staggered inverter (MLI) topology that can expand the quantity of yield voltage levels surprisingly without utilizing any full $\mathrm{H}$-connect cell and furthermore can pass the turn around current for inductive loads[14]-2016.

Power-electronic frameworks for the network combination of sustainable power sources: A review is displayed via Carrasco. The determination of a power-electronic interface is dependent upon necessities related not exclusively to the sustainable power source itself yet in addition to its consequences for the power-framework activity, particularly where the discontinuous vitality source establishes a noteworthy piece of the absolute framework limit. In this work, new inclines in power gadgets for the combination of wind and photovoltaic (PV) control generators are exhibited. An audit of the fitting stockpiling framework innovation utilized for the incorporation of discontinuous sustainable power sources is additionally introduced[16]-2006. [1],[ 3],[5]

DC current infusion into the system from PV lattice inverters is proposed by Salas. The present work is centered around the investigation of the DC current infusion for low voltage little network associated PV frameworks, which is one power quality necessities by the service organizations. For this point the current status of rules and guidelines in six chose nations where the advancement in the framework PV segment has developed quickly in the course of the most recent decade, (Japan, Germany, USA, Australia, Spain and United Kingdom) has been seen, as indicated by the DC current infusion into the lattice. Moreover, a matrix associated framework introduced in Spain has been utilized to perform measures about their conceivable DC current infusion into the $\operatorname{grid}[18]-2006$

A fell staggered inverter dependent on exchanged capacitor for high-recurrence AC control dissemination framework is given by Liu. A tale exchanged capacitor-based fell staggered inverter is proposed in this work, which is developed by an exchanged capacitor frontend and H-Bridge backend. Through the transformation of arrangement and parallel associations, the exchanged capacitor frontend expands the quantity of voltage levels. The yield sounds and the segment counter can be altogether diminished by the expanding number of voltage levels. A balanced triangular waveform balance is proposed with a straightforward simple execution and low tweak recurrence contrasting and customary multicarrier regulation [19]-2014.

\section{RESEARCH GAB}

D-STATCOM is utilized to improve the voltage profile in miniaturized scale lattices. During receptive power remuneration ordinarily STATCOM gives quicker reaction than SVC. D-STATCOM supplies extra driving/slacking Var to the framework to make the voltage consistent at a given transport.

\section{SYSTEM DESCRIPTION}




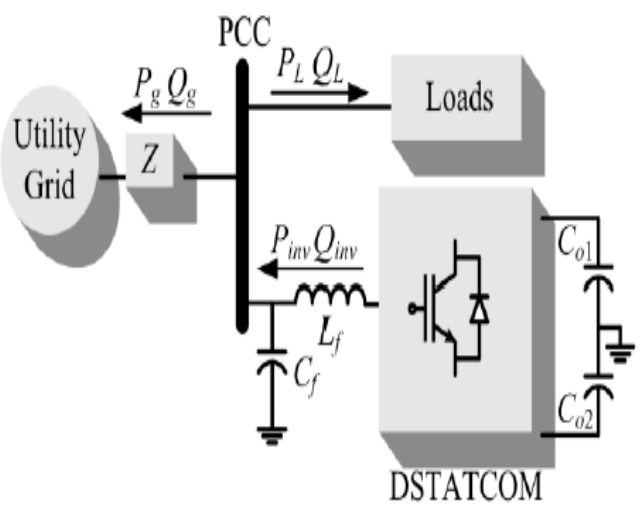

Figure .3 Conventional Block Diagram

\section{SIMULATION RESULTS}

Circuit chart of interleaved help converter with 7-level inverter statcom is showed up in Fig 2.1. The Input Voltage is showed up in Fig 2.2 and its worth is $55 \mathrm{~V}$. Two phase ILBC converter is showed up in Fig 2.3. Exchanging beat for ILBC converter M1 is showed up in Fig 2.4 and its worth is $1 \mathrm{~V}$. ILBC yield voltage is showed up in Fig 2.5 and its worth is $340 \mathrm{~V}$.

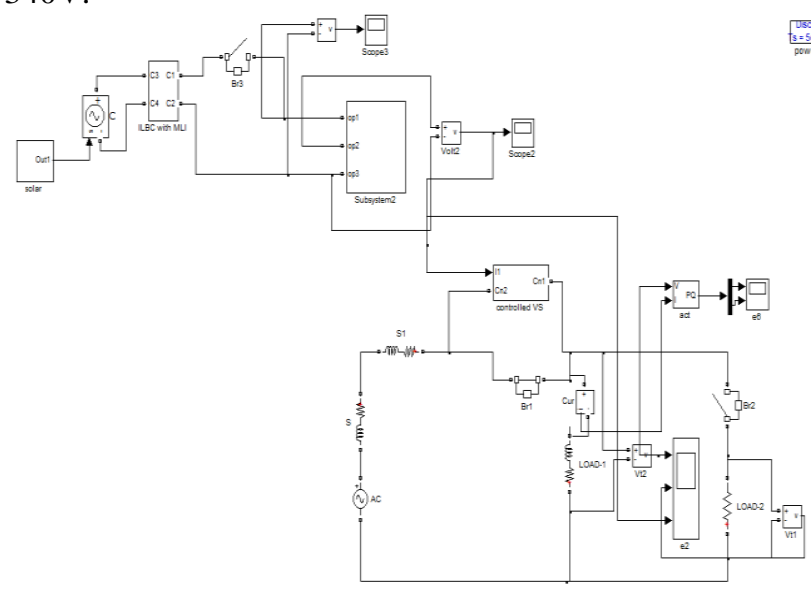

Figure 2.1 Circuit diagram of interleaved boost converter with 7-level inverter statcom

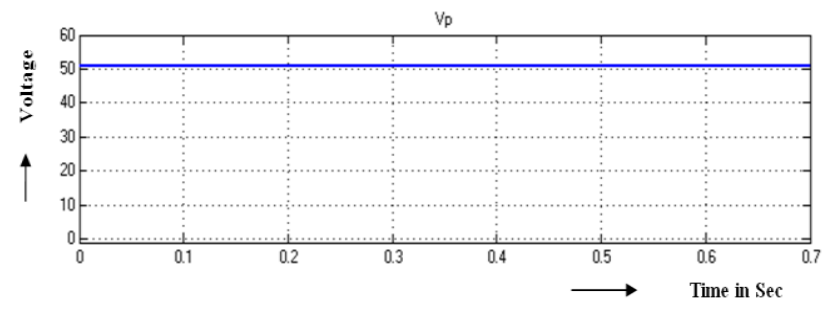

Figure 2.2 Input Voltage

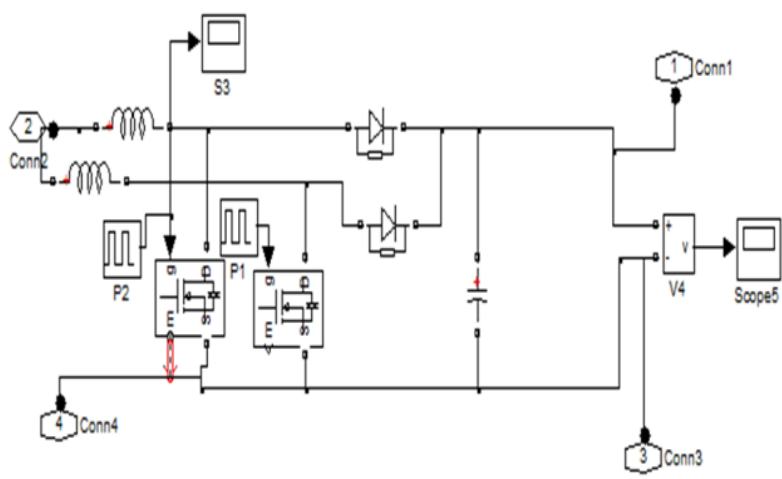

Figure 2.3 Two stage ILBC converter

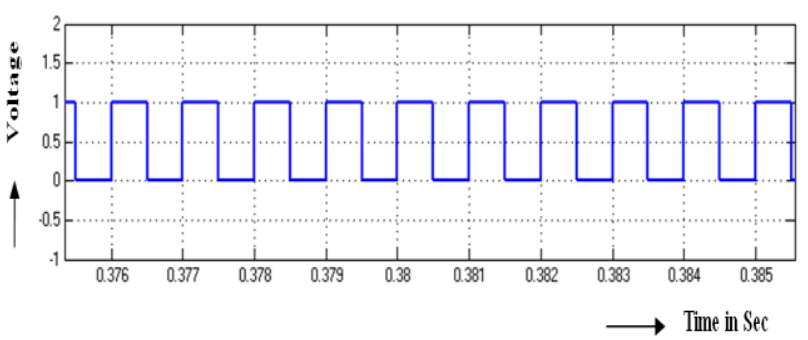

Figure 2.4 Switching pulse for ILBC converter M1

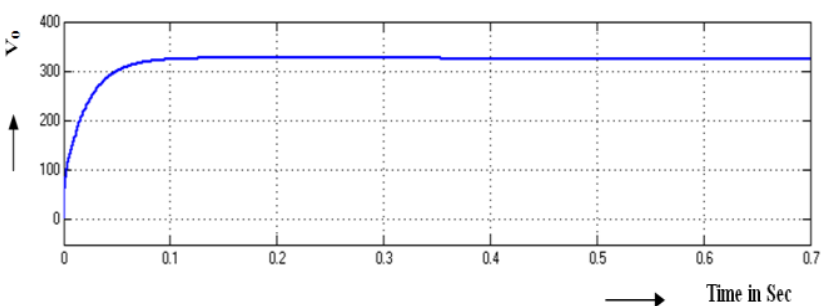

Figure 2.5 ILBC output voltage

Yield swell voltage is showed up in Fig 2.6 and its worth is 326.3675V. Staggered inverter circuit chart is showed up in Fig 2.7. Exchanging beat for staggered inverter switch M1,M3 is showed up in Fig 2.8 and its pinnacle estimation of M1, M3 is $1 \mathrm{~V}$. Staggered inverter yield voltage is showed up in Fig 2.9 and its worth pinnacle worth abatement from 300 to 50 V. Burden 1,load 2 and statcom yield voltage is showed up in Fig 2.10 and its estimation of STATCOM $400 \mathrm{~V}$ and burden 1 , Load 2 Value is $0.7 * 104 \mathrm{~V}$. The Real and receptive power is showed up in Fig 2.11 and genuine power is $2.3 * 105$ VAR and responsive power is 1450 Watts. The Total Harmonic Reduction is showed up in Fig 2.12.

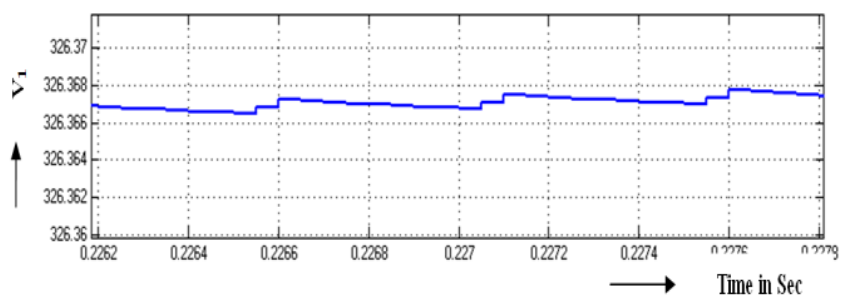

Figure 2.6 Output ripple voltage 


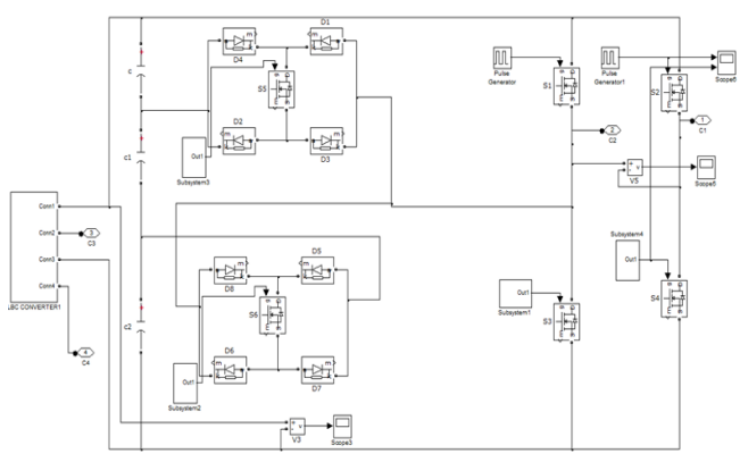

Figure 2.7 Multilevel inverter circuit diagram

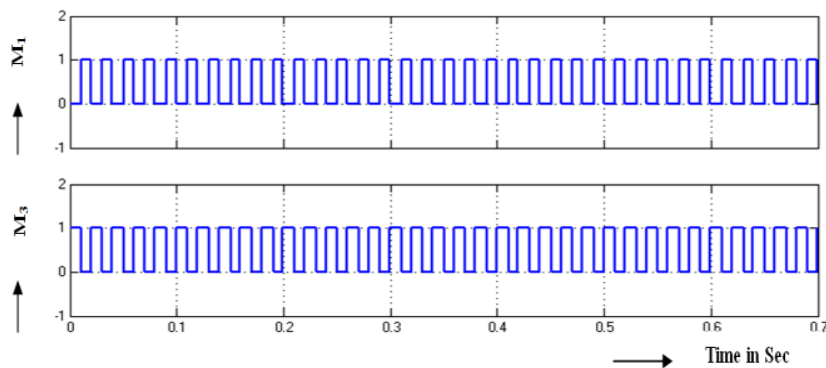

Figure 2.8 Switching pulse for multilevel inverter switch M1,M3

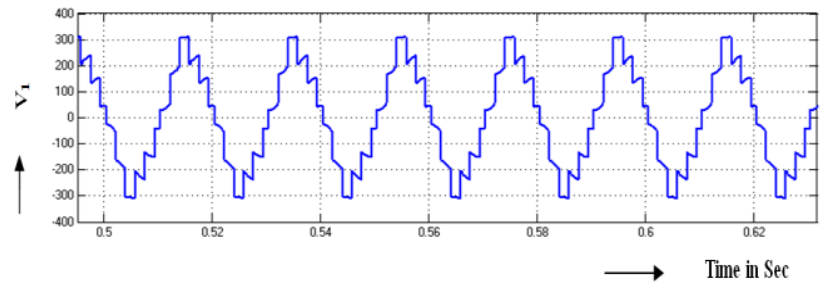

Figure 2.9 Multilevel inverter output voltage

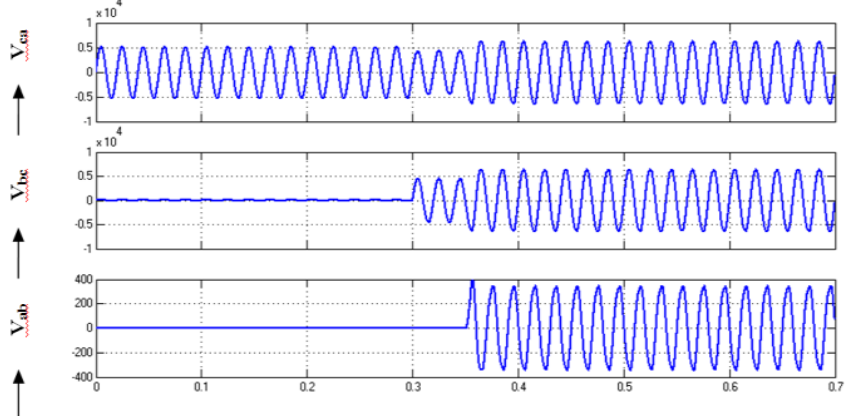

Figure 2.10 Load 1, load2 \& statcom output voltage

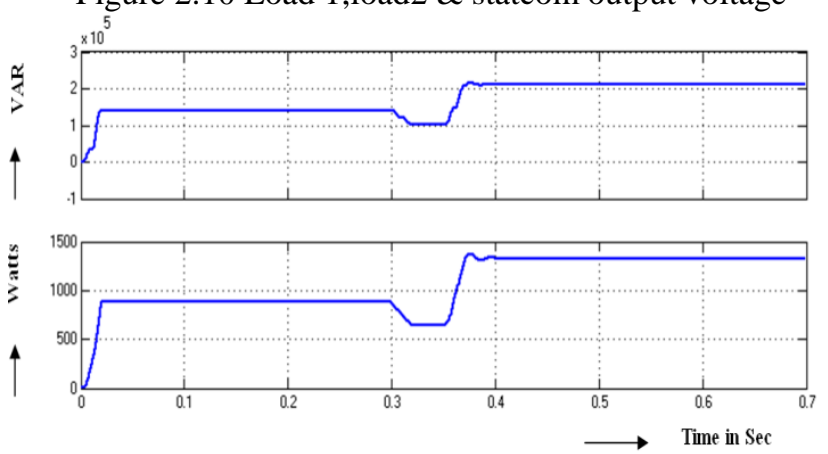

Figure 2.11 Real \& reactive power

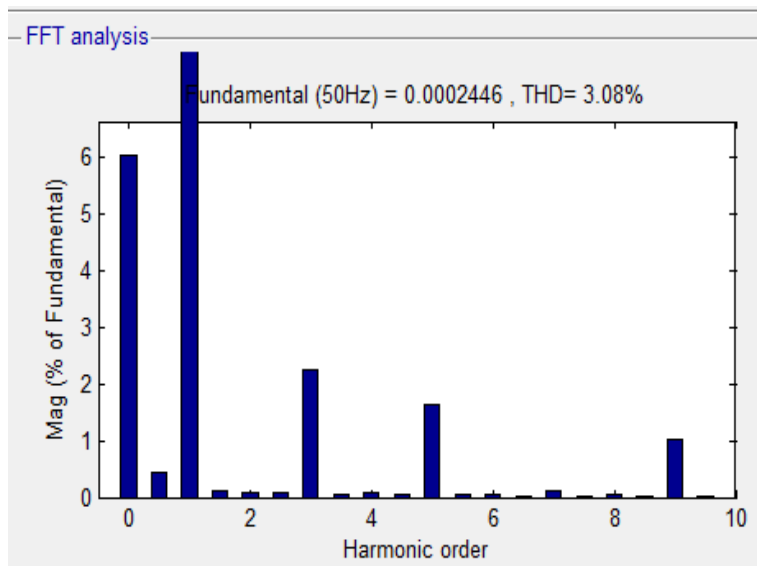

Figure 2.12 THD

Circuit outline of interleaved help converter with 9-level inverter statcom is showed up in Fig 2.13. The Input Voltage is showed up in Fig 2.14 and its worth is $55 \mathrm{~V}$. Two phase ILBC converter is showed up in Fig 2.15. Exchanging beat for ILBC converter M1 is showed up in Fig 2.16 and its worth is $1 \mathrm{~V}$. ILBC yield voltage is showed up in Fig 2.17 and its worth is $360 \mathrm{~V}$. Yield swell voltage is showed up in Fig 2.18 and its worth is $324 \mathrm{~V}$. Exchanging beat for staggered inverter switch M1,M3 is showed up in Fig 2.19 and its pinnacle estimation of M1, M3 is 1V. Staggered inverter yield voltage is showed up in Fig 2.20 and its worth pinnacle worth diminishing from 100 to $-200 \mathrm{~V}$. Burden 1,load2 and statcom yield voltage is showed up in Fig 2.21 and its estimation of STATCOM 1800 $\mathrm{V}$ and burden 1 , Load 2 Value is $0.5 * 104 \mathrm{~V}$. The Real and receptive power is showed up in Fig 2.22 and genuine power is $16 * 105 \mathrm{VAR}$ and responsive power is 12.5 Watts. The Total Harmonic Reduction is showed up in

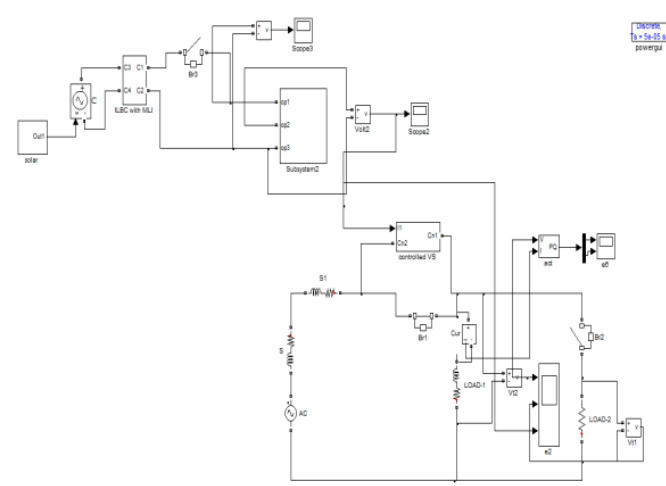

Figure 2.13 Circuit diagram of interleaved boost converter with 9-level inverter statcom 
CapacitorClamped Inverter Based D-STATCOM for Voltage Regulator in Power Quality Improvement for Distribution Grids

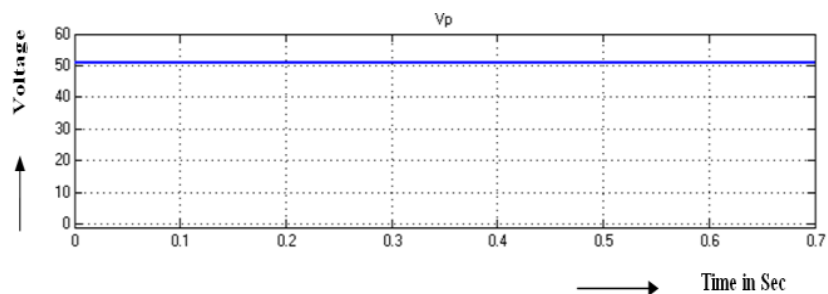

Figure 2.14 Input Voltage

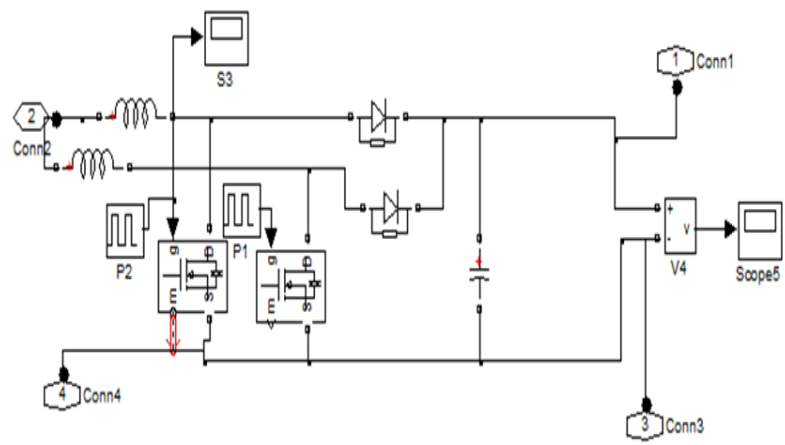

Figure 2.15 Two stage ILBC converter

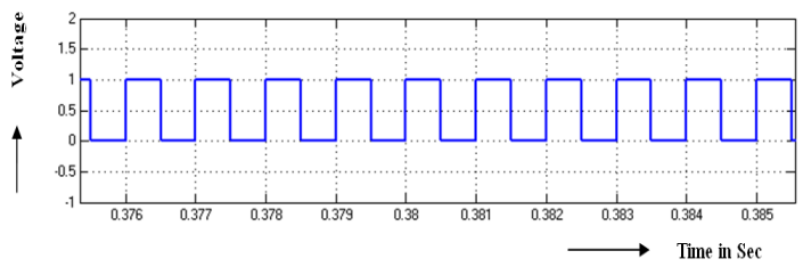

Figure 2.16 Switching pulse for ILBC converter M1

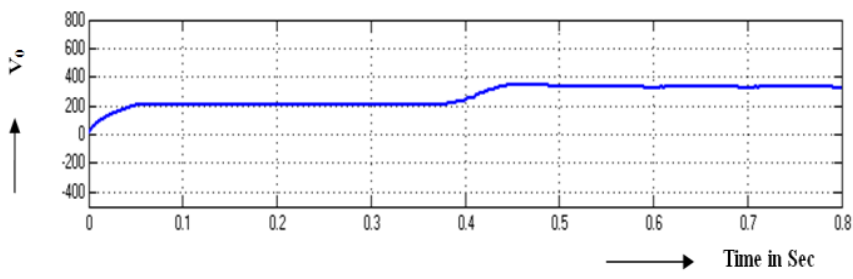

Figure 2.17 ILBC output voltage

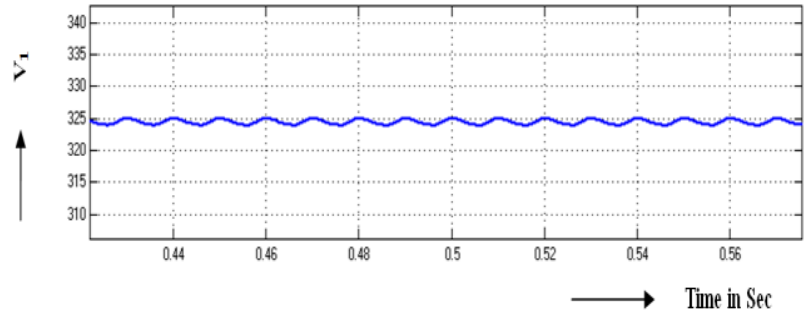

Figure 2.18 Output ripple voltage

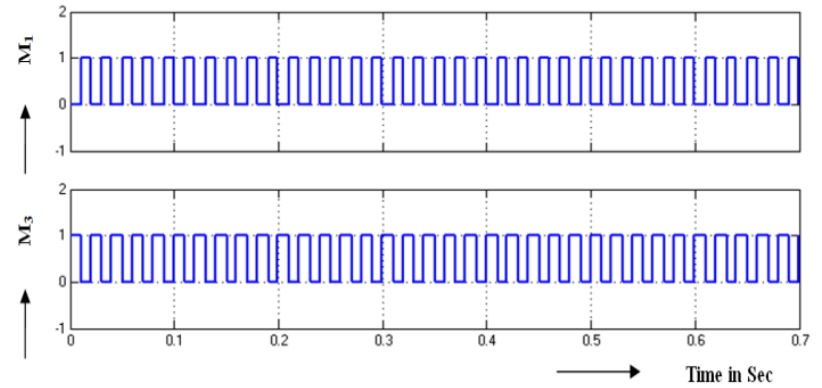

Figure 2.19 Switching pulse for multilevel inverter switch $\mathrm{M} 1, \mathrm{M} 3$

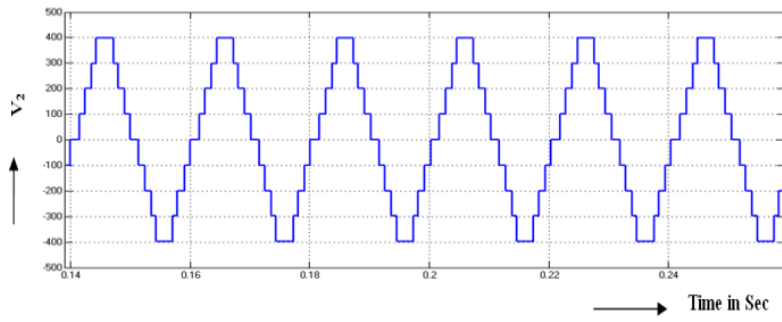

Figure 2.20 Multilevel inverter output voltage

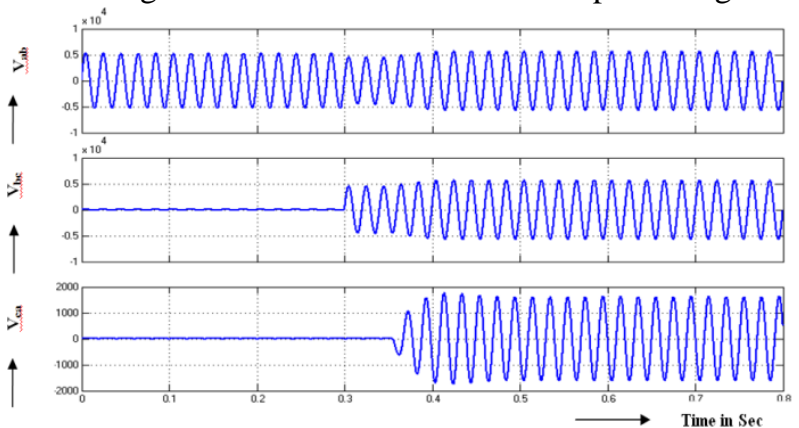

Figure 2.21 Load 1,load2 \& statcom output voltage

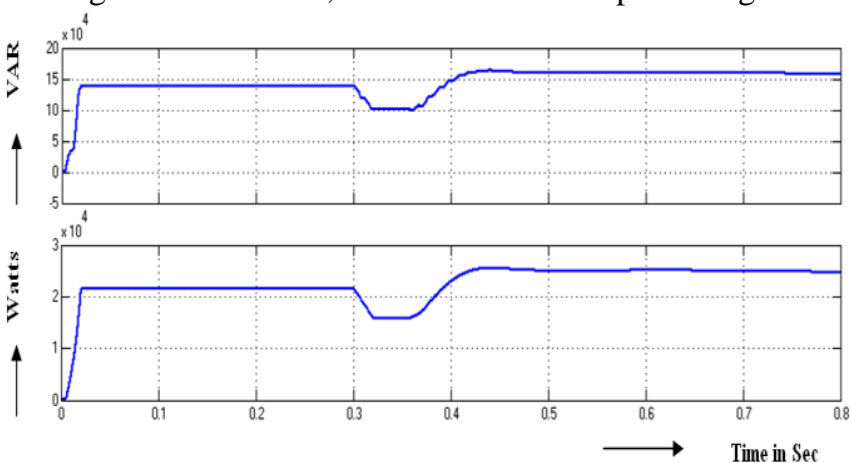

Figure 2.22 Real \& reactive power

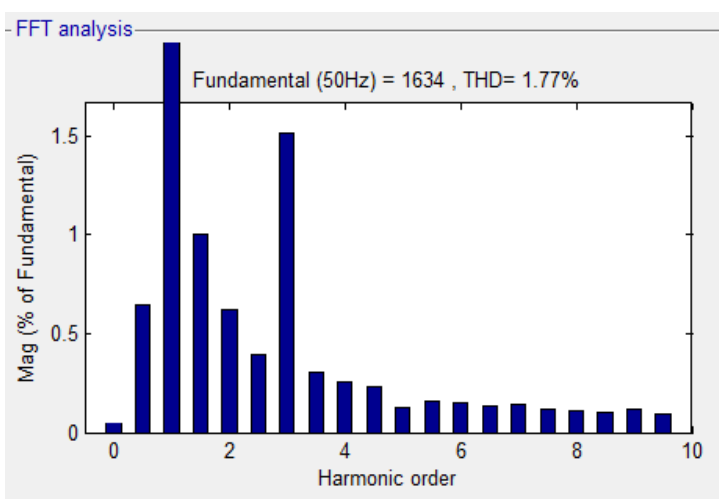

Published By:

Blue Eyes Intelligence Engineering \& Sciences Publication 
Comparsion of output voltage ripple and output current harmonics is given by Table-1. Seven level ILBC converter and Nine level ILBC converter value is $48 \mathrm{~V}$. The Ripple Voltage is Value is $0.09 \mathrm{~V}$ to $0.07 \mathrm{~V}$. The Total Harmonics Reduction value is 3.08 to 1.77 .

TABLE-1 COMPARSION OF OUTPUT VOLTAGE RIPPLE AND OUTPUT CURRENT HARMONIC

\begin{tabular}{|c|c|c|c|}
\hline D-STATCOM & Vin & $\begin{array}{c}\text { Ripple } \\
\text { voltage }\end{array}$ & THD \\
\hline $\begin{array}{c}\text { Seven level } \\
\text { ILBC } \\
\text { converter }\end{array}$ & $48 \mathrm{v}$ & 0.09 & $3.08 \%$ \\
\hline $\begin{array}{c}\text { Nine level } \\
\text { ILBC } \\
\text { converter }\end{array}$ & $48 \mathrm{v}$ & 0.07 & $1.77 \%$ \\
\hline
\end{tabular}

\section{CONCLuSION}

A tale delicate exchanging interleaved coupled-inductor support converter is proposed in this paper. The most straightforward assistant resounding circuit is displayed to understand the ZVT turn-on and littler current mood killer properties of the two fundamental switches. Contrasted with the past interleaved help converter, because of the coupling normal for the information inductors, just a solitary helper full module is sufficient in the proposed converter to accomplish the delicate exchanging capacity of the interleaved coupled-inductor support converter

\section{REFERENCES}

[1] Sharma, R.K., Irusapparajan, G. \& Periyaazhagar, D. 2019, "Three-phase symmetric cascading Z-source seven levels multilevel inverter excited by multi carrier sinusoidal pulse width modulation scheme", International Journal of Innovative Technology and Exploring Engineering, vol. 8, no. 10, pp. 4269-4274.

[2] Velavan, R., Bharanidharan, S. \& Sheeba, B. 2019, "EMF pollution Causes, effects and protection", International Journal of Innovative Technology and Exploring Engineering, vol. 8, no. 9 Special Issue 3, pp. 1166-1168.

[3] Saravana, S., Balaji, S., Arulselvi, S. \& John Paul Praveen, A. 2019, "Reliable power quality monitoring and protection system", International Journal of Innovative Technology and Exploring Engineering, vol. 8, no. 9 Special Issue 3, pp. 644-645.

[4] Tamil Selvan, S. \& Sundararajan, M. 2019, "Performance Parameters of 3 Value 8t Cntfet Based Sram Cell Design Using H-Spice", International Journal of Recent Technology and Engineering, vol. 8, no. 2 Special issue 5, pp. 22-27.

[5] Jac Fredo, A.R., Abilash, R.S., Femi, R., Mythili, A. \& Kumar, C.S 2019, "Classification of damages in composite images using Zernike moments and support vector machines", Composites Part B: Engineering, vol. 168, pp. 77-86.

[6] Kathiravan, P. \& Govindaraju, C. 2019, "Design and evaluation of ultra gain isolated DC-DC converter for photovoltaic system", International Journal of Engineering and Advanced Technology, vol. 8, no. 5, pp. 2646-2651.

[7] Kripa, N., Vasuki, R. \& Kishore Kanna, R. 2019, "Realtime neural interface controlled au-pair BIMA bot", International Journal of Recent Technology and Engineering, vol. 8, no. 1, pp. 992-994.

[8] Mohanraj, Meenaa Kumari, M., Philomina, S. \& Jasmin, M. 2019, "In-situ humidity measurement of hydrogen fuel cell car using MEMS sensor", International Journal of Recent Technology and Engineering, vol. 8 , no. 1, pp. 41-43.

[9] Velmurugan, T. \& Prakash, S. 2019, "Artificial intelligent based distribution automation of swift fault detection isolation and power restoration for HT network", International Journal of Innovative Technology and Exploring Engineering, vol. 8, no. 6, pp. 1-6.

[10] Dwarakesh, K. \& Prem Kumar, G. 2019, "Five-level inverter based sequential boost system using fuzzy logic controller", International Journal of Innovative Technology and Exploring Engineering, vol. 8, no. 6, pp. 12-19.
[11] Anne Gifta, A. \& Hemavathi, G. 2019, "Analysis of grid tied solar PV system using ANFIS Algorithm", International Journal of Innovative Technology and Exploring Engineering, vol. 8, no. 6, pp. 312-316.

[12] Jayavel, R., Rangaswamy, T.R. \& Prakash, S. 2019, "Efficient gric management system with renewable and conventional power sources", International Journal of Innovative Technology and Exploring Engineering, vol. 8, no. 6, pp. 287-289.

[13] Hemavathi, G. \& Maheshwaran, S. 2019, "Proportional resonant controlled high gain step-up converter system with improved response", International Journal of Innovative Technology and Exploring Engineering, vol. 8, no. 6, pp. 317-323.

[14] Periyaazhagar, D. \& Irusapparajan, G. 2019, "Design and completion of asymmetric single phase 27 level cascaded mli for various pwm scheme", International Journal of Innovative Technology and Exploring Engineering, vol. 8, no. 6, pp. 792-797.

[15] Mahalakshmi, V. \& Vijayaragavan, S.P. 2019, "PV based power electronic converters for high voltage DC applications", International Journal of Recent Technology and Engineering, vol. 7, no. 6, pp. 670-674.

[16] Irusapparajan, G., Periyaazhagar, D., Prabaharan, N. \& Rini Ann Jerin, A. 2019, "Experimental verification of trinary DC source cascaded h-bridge multilevel inverter using unipolar pulse width modulation", Automatika, vol. 60, no. 1, pp. 19-27.

[17] Sangeetha, G., Sherine, S., Arputharaju, K. \& Prakash, S. 2019, "On Line Monitoring of Higher Rated Alternator using Automated Generator Capability Curve Administer", Proceedings of the IEEE International Conference on \&amp;quot;Recent Trends in Electrical, Control and Communication\&amp;quot;, RTECC 2018, pp. 176.

[18] Bycil, V.J. \& Wiselin, M.C.J. 2019, "Modeling and analysis of vibration energy harvesting system using piezo stack", International Journal of Mechanical and Production Engineering Research and Development, vol. 9, no. Special Issue 1, pp. 523-533.

[19] Sripada, A., Warrier, A., Kapoor, A., Gaur, H. \& Hemalatha, B. 2018, "Dynamic lateral balance of humanoid robots on unstable surfaces", International Conference on Electrical, Electronics, Communication Computer Technologies and Optimization Techniques, ICEECCOT 2017 , pp. 539.

[20] Srinivasan, S., Thirumalaivasan, K. \& Sivakumaran, T.S. 2018 , "Performance evaluation of double-output luo converters", Journal of Advanced Research in Dynamical and Control Systems, vol. 10, no. 10 Special Issue, pp. 870-878.

[21] Karthikayen, A. \& Selvakumar Raja, S. 2018, "A skellam distribution inspired trust factor-based selfish node detection technique in MANETs", Journal of Advanced Research in Dynamical and Control Systems, vol. 10, no. 13, pp. 940-949.

\section{AUTHORS PROFILE}

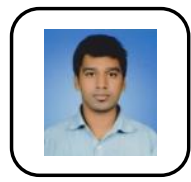

K.Dwarakesh,Assistant Professor, Department of EEE,Bharath Institute of Higher education and research, Tamilnadu, India.

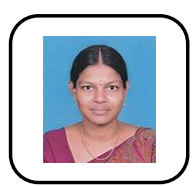

Rathika R,Assistant Professor, Department of EEE,Bharath Institute of Higher education and research, Tamilnadu, India.

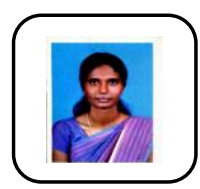

Aarthi Suriya S,Assistant Professor, Department of EEE, Bharath Institute of Higher education and Research, Tamilnadu, India. 